\title{
Dental Anthropological Study of Chinese Ethnic Minority, Miao, with Reference to Other Minorities and Asian Populations
}

\author{
Mariko Yamashita, Roshan Peiris, and Masanobu Matsuno
}

Department of Anatomy and Physical Anthropology, Nihon University School of Dentistry at Matsudo, Matsudo, Chiba 271-8587, Japan

Correspondence to :

Masanobu Matsuno

E-mail : matsuno.masanobu@nihon-

u.ac.jp

\section{Keywords :}

Chinese minority, Miao, dental traits, tooth size, Yunnan, dental anthropology

\begin{abstract}
Department of Anatomy and Physical Anthropology, Nihon University School of Dntistry at Matsudo made a dental anthropological survey of a Chinese minority in Annin in Yunnan Province in 2007. Subjects were young adults of the Miao people historically derived from Southeast Asian area from whom dental impression models were collected. The frequencies of 22 dental non-metric traits of 7 maxillary and 4 mandibular teeth were recorded. Measurements of the teeth were also made by a digital caliper with the precision of $1 / 100 \mathrm{~mm}$ on mesiodistal and buccolingual diameters of each tooth. The results were compared with those of previous studies including Chinese minorities, Dai, Hani and Naxi, Pumi and with other Asian populations. A principal coordinate analysis based on Smith's Mean Measure of Divergence using the frequencies of 17 traits suggested that the Miao belonged to the Sundadont dentition category, which typifies Southeast Asians and positioned close to the Hani. Statistics and multi-variate analysis of the metric study showed that the Miao had relatively small teeth compared with other four minorities in Yunnan Province. Based on our findings, and presumed past and present distributions of Sinodonty and Sundadonty, it was suggested that the Miao in Yunnan Province have genetically inherited traits similar to the Sundadont peoples of Southeast Asian to which other four minorities also belonged. However, different combination of the frequent dental traits and small size of the teeth in Miao might suggest that the Miao occupies a different position of their affinity from other four minorities.
\end{abstract}

\section{Introduction}

There are 55 ethnic minorities in China, most of which have been living in Yunnan Province (1). Physical anthropological studies such as anthropometry and craniometry on these groups have been accomplished mainly by Chinese Academy (2, 3, 4). However, dental anthropological characteristics of these groups have not been fully studied. Dental morphology and odontometry occupy an important position in anthropological investigations for reconstruction of ethnic affinities among these minorities and the relationships between these tribes and peoples in Asia. In recent years, dental anthropological studies for 4 Chinese minorities, the Dai, Hani, Naxi and Pumi tribe were carried out by Nihon University Dental Survey Team in 2000, 2002 at Yuen Jian and Li Jian in Yunnan Province, China in which both metric and non-metric studies were carried out $(5,6$, 7). These studies showed that the tooth sizes were relatively small and that the non-metric traits showed Sundadont characteristics.

The Miao ethnic minority is another ethnic group with relatively large population in Yunnan Province. However, their dental anthropological characters have not been reported yet. The purposes of this study were to describe the frequencies of dental traits and the size of the teeth of Miao people and to compare them with other minorities and Asian peo- 
ples in multivariate analysis.

\section{Materials and Methods}

Materials were dental plaster casts of permanent dentition collected from Miao villagers at the city of Anning near Kunming. They were 16 to 28 years of age being mainly engaged in agricultural work on vegetables and tobacco leaf. Dental traits for observation were well preserved in this age range without severe attrition.

Dental casts of the Miao (38 males and 62 females) were stored in Nihon University School of Dentistry at Matsudo. The parameters recorded in this study were 22 crown traits classified by the Arizona State University Dental Anthropology System (8). These are listed in Table 1 to Table 22, where the grades or scores for each trait are also shown. Most of these traits have previously been used to explicate modes of inheritance and heritability, and the frequencies of these traits can be regarded as population characteristics $(8,9,10)$. The data from males and females were pooled because there were no significant differences (at 5\% level) between the sexes in the frequencies of all 22 traits measured in this study.

Table 1. Teeth and frequencies of shoveling in the Miao (sexes pooled).

\begin{tabular}{lrrrr} 
& \multicolumn{2}{c}{ UI1 } & \multicolumn{2}{c}{ UI2 } \\
Expression & \multicolumn{1}{c}{ N } & \multicolumn{1}{c}{$\%$} & \multicolumn{1}{c}{$\%$} \\
\hline$-:$ None & 8 & 8.51 & 2 & 2.22 \\
$\pm:$ Trace & 28 & 29.79 & 35 & 38.89 \\
+ : Present & 51 & 54.26 & 44 & 48.89 \\
++ : Strong & 5 & 5.32 & 3 & 3.33 \\
Total & 92 & & 84 & \\
\hline
\end{tabular}

Table 2. Teeth and frequencies of double-shoveling in the Miao (sexes pooled).

\begin{tabular}{lrrrr} 
& \multicolumn{2}{c}{ UI1 } & \multicolumn{2}{c}{ UI2 } \\
Expression & $\mathrm{N}$ & \multicolumn{1}{c}{$\%$} & \multicolumn{1}{c}{$\mathrm{N}$} & \multicolumn{1}{c}{$\%$} \\
\hline$-:$ None & 29 & 30.85 & 59 & 64.13 \\
$\pm:$ Trace & 49 & 52.13 & 24 & 26.09 \\
+ : Present & 16 & 17.02 & 2 & 2.17 \\
++ : Strong & 0 & 0.00 & 0 & 0.00 \\
Total & 94 & & 85 & \\
\hline
\end{tabular}

A four-point scale was used for scoring of the traits involving none $(-)$, trace $( \pm)$, present $(+)$ and strong $(++)$, except for the following cases: interruption groove and winging in the upper incisor (6point and 5-point scales respectively), odontome in the premolars (2-point scale i.e. present or absent), lingual cusp variation in the lower molars and hypocone reduction in the upper molars (4 levels based on a combination of cusp numbers and their size), Carabelli's trait in the upper molars (5-point scale), and distal trigonid crest in the lower molars and cusp number in the lower molar (2-point scales).

In the comparison of the Miao frequencies with those of the 30 other East Asian populations, the number of crown parameters was reduced to 17 , and the number of levels in the various scales was reduced to two, with all points above $1(2-4,2-5,2-6)$ combined into one score (7). Thus the frequencies for each parameter were expressed simply as present or absent. Using the frequencies of the 17 traits, Smith's Mean Measure of Divergence (MMD), together with the Freeman-Tukey method for inverse sine transformation, was used to determine inter-population distances, $(11,12,13)$. Affinity between the Miao and

Table 3. Teeth and frequencies of tuberculum dentale in the Miao (sexes pooled).

\begin{tabular}{lrrrrrr} 
& \multicolumn{2}{c}{ UI1 } & \multicolumn{2}{c}{ UI2 } & \multicolumn{2}{c}{ UC } \\
Expression & \multicolumn{1}{c}{$\%$} & \multicolumn{1}{c}{ N } & \multicolumn{1}{c}{$\%$} & \multicolumn{1}{c}{ N } & \multicolumn{1}{c}{} \\
\hline$-:$ None & 53 & 56.99 & 81 & 96.43 & 27 & 27.84 \\
$\pm:$ Trace & 30 & 32.26 & 1 & 1.19 & 59 & 60.82 \\
+ : Present & 11 & 11.83 & 2 & 2.38 & 11 & 11.34 \\
++ : Strong & 0 & 0.00 & 0 & 0.00 & 0 & 0.00 \\
Total & 94 & & 84 & & 97 & \\
\hline
\end{tabular}

Table 4. Teeth and frequencies of spinal process in the Miao (sexes pooled).

\begin{tabular}{lrrrr} 
& \multicolumn{2}{c}{ UI1 } & \multicolumn{2}{c}{ UI2 } \\
Expression & \multicolumn{1}{c}{$\mathrm{N}$} & \multicolumn{1}{c}{$\%$} & \multicolumn{1}{c}{$\%$} \\
\hline$-:$ None & 87 & 93.55 & 82 & 96.47 \\
$\pm:$ Trace & 5 & 5.38 & 2 & 2.35 \\
+ : Present & 1 & 1.08 & 1 & 1.18 \\
++ : Strong & 0 & 0.00 & 0 & 0.00 \\
Total & 93 & & 85 & \\
\hline
\end{tabular}


Table 5. Teeth and frequencies of interruption groove in the Miao (sexes pooled).

\begin{tabular}{lrrrr} 
& \multicolumn{2}{c}{ UI1 } & \multicolumn{2}{c}{ UI2 } \\
Expression & N & $\%$ & N & $\%$ \\
\hline$-:$ None & 93 & 100 & 79 & 92.94 \\
MB : Mesiolingual border & 0 & 0.00 & 4 & 4.71 \\
DB : Distlingual border & 0 & 0.00 & 1 & 1.18 \\
MD : Mesio and distlingual border & 0 & 0.00 & 1 & 1.18 \\
MA : Mesial area & 0 & 0.00 & 0 & 0.00 \\
DA : Distal area & 0 & 0.00 & 0 & 0.00 \\
Total & 93 & & 85 & \\
\hline
\end{tabular}

Table 6. Teeth and frequencies of winging in the Miao (sexes pooled).

\begin{tabular}{lcc} 
& \multicolumn{2}{c}{ UI1 } \\
Expression & $\mathrm{N}$ & $\%$ \\
\hline $\mathrm{C}+:$ Present (counter winging) & 12 & 12.63 \\
$\mathrm{C} \pm:$ Trace (counter winging) & 15 & 15.79 \\
$-:$ None & 45 & 47.37 \\
$\pm:$ Trace & 12 & 12.63 \\
$\quad+:$ Present & 11 & 11.58 \\
Total & 95 & \\
\hline
\end{tabular}

Table 7. Teeth and frequencies of canine mesial ridge in the Miao (sexes pooled).

\begin{tabular}{lrr} 
& \multicolumn{3}{c}{$\mathrm{UC}$} \\
Expression & $\mathrm{N}$ & \multicolumn{1}{c}{$\%$} \\
\hline$-:$ None & 82 & 87.23 \\
$\pm:$ Trace & 5 & 5.32 \\
$+:$ Present & 6 & 6.38 \\
++ : Strong & 1 & 1.06 \\
Total & 94 & \\
\hline
\end{tabular}

Table 8. Teeth and frequencies of canine distal accessory ridge in the Miao (sexes pooled).

\begin{tabular}{lrr} 
& \multicolumn{2}{c}{ UC } \\
Expression & $\mathrm{N}$ & $\%$ \\
\hline$-:$ None & 52 & 59.77 \\
$\pm:$ Trace & 25 & 28.74 \\
$+:$ Present & 10 & 11.49 \\
$++:$ Strong & 0 & 0.00 \\
Total & 87 & \\
\hline
\end{tabular}

Table 9. Teeth and frequencies of accessory marginal tubercle in the Miao (sexes pooled).

\begin{tabular}{lrrrr} 
& \multicolumn{3}{c}{ UP1 } & \multicolumn{2}{c}{ UP2 } \\
Expression & $\mathrm{N}$ & \multicolumn{1}{c}{$\%$} & \multicolumn{1}{c}{$\mathrm{N}$} & \multicolumn{1}{c}{$\%$} \\
\hline$-:$ None & 30 & 32.26 & 55 & 66.27 \\
$\pm:$ Trace & 31 & 33.33 & 12 & 14.46 \\
$\quad+:$ Present & 32 & 34.41 & 11 & 13.25 \\
$++:$ Strong & 0 & 0.00 & 5 & 6.02 \\
Total & 93 & & 83 & \\
\hline
\end{tabular}

Table 10. Teeth and frequencies of odontomes in the Miao (sexes pooled).

\begin{tabular}{lrrrrrrrr} 
& \multicolumn{2}{c}{ UP1 } & \multicolumn{2}{c}{ UP2 } & \multicolumn{2}{c}{ LP1 } & \multicolumn{2}{c}{ LP2 } \\
Expression & $\mathrm{N}$ & $\%$ & $\mathrm{~N}$ & $\%$ & \multicolumn{1}{c}{$\mathrm{N}$} & $\%$ & $\mathrm{~N}$ & $\%$ \\
\hline - : None & 100 & 100 & 98 & 100 & 95 & 97.94 & 96 & 97.96 \\
$\quad$ + Present & 0 & 0.00 & 0 & 0.00 & 2 & 2.06 & 2 & 2.04 \\
Total & 100 & & 98 & & 97 & & 98 & \\
\hline
\end{tabular}

Table 11. Teeth and frequencies of lingual cusp variation in the Miao (sexes pooled).

\begin{tabular}{lrrrr} 
& \multicolumn{2}{c}{ LP1 } & \multicolumn{2}{c}{ LP2 } \\
Expression & $\mathrm{N}$ & \multicolumn{1}{c}{$\%$} & \multicolumn{1}{c}{$\mathrm{N}$} & \multicolumn{1}{c}{$\%$} \\
\hline 0: None & 7 & 7.14 & 0 & 0.00 \\
1: One lingual cusp & 81 & 82.65 & 61 & 61.62 \\
2: Two lingual cusp & 10 & 10.20 & 38 & 38.38 \\
3: Three lingual cusp & 0 & 0.00 & 0 & 0.00 \\
Total & 98 & & 99 & \\
\hline
\end{tabular}

Table 12. Teeth and frequencies of hypocone reduction in the Miao (sexes pooled).

\begin{tabular}{lrrrr} 
& \multicolumn{2}{c}{ UM1 } & \multicolumn{2}{c}{ UM2 } \\
Expression & \multicolumn{1}{c}{ N } & \multicolumn{1}{c}{ N } & \multicolumn{1}{c}{$\%$} \\
\hline 4+ : Large cusp & 73 & 78.49 & 5 & 5.68 \\
$4-:$ Small cusp & 16 & 17.20 & 23 & 26.14 \\
3+ : Faint cusp & 4 & 4.30 & 37 & 42.05 \\
3- : None or faint ridge & 0 & 0.00 & 23 & 26.14 \\
Total & 93 & & 88 & \\
\hline
\end{tabular}


Table 13. Teeth and frequencies of metacone reduction in the Miao (sexes pooled).

\begin{tabular}{lrrrr} 
& \multicolumn{3}{c}{ UM1 } & \multicolumn{2}{c}{ UM2 } \\
Expression & $\mathrm{N}$ & $\%$ & \multicolumn{1}{c}{$\mathrm{N}$} & \multicolumn{1}{c}{$\%$} \\
\hline$-:$ None & 81 & 88.04 & 9 & 10.23 \\
$\pm:$ Trace & 11 & 11.96 & 53 & 60.23 \\
+ : Present & 0 & 0.00 & 26 & 29.55 \\
$++:$ Strong & 0 & 0.00 & 0 & 0.00 \\
Total & 92 & & 88 & \\
\hline
\end{tabular}

Table 14. Teeth and frequencies of cusp 5 in the Miao (sexes pooled).

\begin{tabular}{lrrrr} 
& \multicolumn{3}{c}{ UM1 } & \multicolumn{2}{c}{ UM2 } \\
Expression & \multicolumn{1}{c}{$\%$} & \multicolumn{1}{c}{ N } & \multicolumn{1}{c}{$\%$} \\
\hline$-:$ None & 69 & 83.13 & 77 & 90.59 \\
$\pm:$ Trace & 8 & 9.64 & 4 & 4.71 \\
$\quad+:$ Present & 6 & 7.23 & 4 & 4.71 \\
++ : Strong & 0 & 0.00 & 0 & 0.00 \\
Total & 83 & & 85 & \\
\hline
\end{tabular}

Table 15. Teeth and frequencies of Carabelli's trait in the Miao (sexes pooled).

\begin{tabular}{lrrrr} 
& \multicolumn{2}{c}{ UM1 } & \multicolumn{2}{c}{ UM2 } \\
Expression & \multicolumn{1}{c}{ N } & \multicolumn{1}{c}{$\%$} & \multicolumn{1}{c}{ N } & \multicolumn{1}{c}{$\%$} \\
\hline$-:$ None & 58 & 60.42 & 91 & 92.86 \\
$\pm:$ Line & 13 & 13.54 & 2 & 2.04 \\
$\pm:$ Trace & 15 & 15.63 & 4 & 4.08 \\
$\quad+:$ Tubercle & 9 & 9.38 & 1 & 1.02 \\
$++:$ Cusp & 1 & 1.04 & 0 & 0.00 \\
Total & 96 & & 98 & \\
\hline
\end{tabular}

Table 16. Teeth and frequencies of protostylid in the Miao (sexes pooled).

\begin{tabular}{lrrrr} 
& \multicolumn{2}{c}{ LM1 } & \multicolumn{2}{c}{ LM2 } \\
Expression & \multicolumn{1}{c}{ N } & \multicolumn{1}{c}{ N } & \multicolumn{1}{c}{$\%$} \\
\hline$-:$ None & 75 & 82.42 & 88 & 91.67 \\
$\pm:$ Trace & 14 & 15.38 & 6 & 6.25 \\
$+:$ Tubercle & 2 & 2.20 & 2 & 2.08 \\
$++:$ Cusp & 0 & 0.00 & 0 & 0.00 \\
Total & 91 & & 96 & \\
\hline
\end{tabular}

Table 17. Teeth and frequencies of deflecting wrinkle in the Miao (sexes pooled).

\begin{tabular}{lrrrr} 
& \multicolumn{2}{c}{ LM1 } & \multicolumn{2}{c}{ LM2 } \\
Expression & $\mathrm{N}$ & \multicolumn{1}{c}{$\%$} & \multicolumn{1}{c}{$\mathrm{N}$} & \multicolumn{1}{c}{$\%$} \\
\hline$-:$ None & 45 & 56.25 & 87 & 96.67 \\
$\pm:$ Trace & 25 & 31.25 & 3 & 3.33 \\
+ : Present & 10 & 12.50 & 0 & 0.00 \\
$++:$ Strong & 0 & 0.00 & 0 & 0.00 \\
Total & 80 & & 90 & \\
\hline
\end{tabular}

Table 18. Teeth and frequencies of distal trigonid crest in the Miao (sexes pooled).

\begin{tabular}{crrrr} 
& \multicolumn{3}{c}{ LM1 } & \multicolumn{2}{c}{ LM2 } \\
Expression & $\mathrm{N}$ & $\%$ & $\mathrm{~N}$ & $\%$ \\
\hline$-:$ Abcent & 82 & 100 & 92 & 100 \\
$+:$ Present & 0 & 0.00 & 0 & 0.00 \\
Total & 82 & & 92 & \\
\hline
\end{tabular}

Table 19. Teeth and frequencies of cusp 6 in the Miao (sexes pooled).

\begin{tabular}{lrrrr} 
& \multicolumn{2}{c}{ LM1 } & \multicolumn{2}{c}{ LM2 } \\
Expression & $\mathrm{N}$ & $\%$ & \multicolumn{1}{c}{$\mathrm{N}$} & \multicolumn{1}{c}{$\%$} \\
\hline$-:$ None & 44 & 64.71 & 47 & 74.60 \\
$\pm:$ C5 $>$ C6 & 10 & 14.71 & 5 & 7.94 \\
$+:$ C5 $=$ C6 & 11 & 16.18 & 9 & 14.29 \\
$++:$ C5 $<$ C6 & 3 & 4.41 & 2 & 3.17 \\
Total & 68 & & 63 & \\
\hline
\end{tabular}

Table 20. Teeth and frequencies of cusp 7 in the Miao (sexes pooled).

\begin{tabular}{lrrrr} 
& \multicolumn{2}{c}{ LM1 } & \multicolumn{2}{c}{ LM2 } \\
Expression & \multicolumn{1}{c}{$\%$} & \multicolumn{1}{c}{$\mathrm{N}$} & \multicolumn{1}{c}{$\%$} \\
\hline$-:$ None & 84 & 94.38 & 92 & 98.92 \\
$\pm:$ Faint cusp & 1 & 1.12 & 0 & 0.00 \\
$\quad+:$ Small cusp & 4 & 4.49 & 1 & 1.08 \\
++ : Large cusp & 0 & 0.00 & 0 & 0.00 \\
Total & 89 & & 93 & \\
\hline
\end{tabular}

Table 21. Teeth and frequencies of groove pattern in the Miao (sexes pooled).

\begin{tabular}{lrrrr} 
& \multicolumn{2}{c}{ LM1 } & \multicolumn{2}{c}{ LM2 } \\
Expression & \multicolumn{1}{c}{$\%$} & \multicolumn{1}{c}{ N } & $\%$ \\
\hline Y pattern & 65 & 86.67 & 8 & 10.39 \\
+ pattern & 8 & 10.67 & 36 & 46.75 \\
X pattern & 2 & 2.67 & 33 & 42.86 \\
Total & 75 & & 77 & \\
\hline
\end{tabular}


Table 22. Teeth and frequencies of cusp number in the Miao (sexes pooled).

\begin{tabular}{lrrrc} 
& \multicolumn{2}{c}{ LM1 } & \multicolumn{2}{c}{ LM2 } \\
Expression & $\mathrm{N}$ & $\%$ & $\mathrm{~N}$ & $\%$ \\
\hline $4: 4$ cusp & 0 & 0.00 & 12 & 17.65 \\
$5: 5$ cusp & 78 & 100 & 56 & 82.35 \\
Total & 78 & & 68 & \\
\hline
\end{tabular}

other Asian populations was expressed on two dimensions of the principal coordinate analysis based on Smith's MMD.

For metric study, the teeth on the right side of the maxillary and mandibular arches were measured except for third molars by digital calipers with the accuracy of $0.01 \mathrm{~mm}$. Any tooth with obvious dental abnormalities, excessive wear, caries, impression flaws, partial eruption, or fillings that obscured the proper placement of caliper beaks was excluded. When a tooth on the right side was not available according to these disturbances, corresponding tooth on the left side was measured.

The statistical test, i.e., the MMD, the principal coordinate analysis, and the $\mathrm{Chi}^{-}$square test for sex differences, Student's t-test were all carried out on a personal computer using the JMP statistical package (SAS Institute Inc. ver. 6).

\section{Results}

The frequencies of the 22 non-metric traits of the upper and lower dentition were shown in Table 1 to Table 22. They are expressed by individual count and percentage. Because of differences in the number of observable cases, total sample numbers differ from trait to trait. Table 23 shows the dichotomized frequencies of the 17 analyzed traits in the Miao to compare with those of other Asian populations. Hypocone reduction at the levels of 4 and 3 in upper second molar had the highest frequency among the 17 traits. Deflecting wrinkle and distal trigonid crest in the lower first molar had the lowest frequency at 0.0 .

Dichotomized frequencies of the 17 traits in 30 populations of East Asia and those of the Miao tribe are shown in Table 24. Frequencies for the populations other than the Miao were taken from already published studies $(9,14-24)$. The traits which showed a relatively high frequency in the Miao compared with other Chinese minorities, the Dai, Hani, Naxi and Pumi were hypocone reduction in UM1, Cusp 6

Table 23. Dichotomized frequency of 17 selected traits in the Miao

\begin{tabular}{lllr}
\hline \multicolumn{1}{c}{ Trait } & \multicolumn{1}{c}{ Tooth } & \multicolumn{1}{c}{ Expression dichotomy* } & Frequency in Miao (\%) \\
\hline Shoveling & UI1 & $(++,+) /(++\sim-)$ & 60.87 \\
Double-shoveling & UI1 & $(++,+) /(++\sim-)$ & 17.02 \\
Tuberculum dentale & UI2 & $(++\sim \pm) /(++\sim-)$ & 3.57 \\
Mesial ridge & UC & $(++\sim \pm) /(++\sim-)$ & 12.77 \\
Distal accessory ridge & UC & $(++\sim \pm) /(++\sim-)$ & 40.23 \\
Lingual cusp variation & LP2 & $(3,2) /(3 \sim 0)$ & 38.38 \\
Odontomes & U-L, P1-2 & $(+) /(+,-)$ & 2.06 \\
Hypocone & UM2 & $(4+\sim 3+) /(4+\sim 3-)$ & 73.86 \\
Cusp 5 & UM1 & $(++\sim \pm) /(++\sim-)$ & 16.87 \\
Carabelli's trait & UM1 & $(++,+) /(++\sim-)$ & 10.42 \\
Protostylid & LM1 & $(++\sim \pm) /(++\sim-)$ & 17.58 \\
Deflecting wrinkle & LM1 & $(++) /(++\sim-)$ & 0.00 \\
Distal trigonid crest & LM1 & $(+) /(+,-)$ & 0.00 \\
Cusp 6 & LM1 & $(++\sim \pm) /(++\sim-)$ & 35.29 \\
Cusp 7 & LM1 & $(++\sim \pm) /(++\sim-)$ & 5.62 \\
Y groove pattern & LM2 & $(\mathrm{Y}) /(\mathrm{Y},+, \mathrm{X})$ & 10.39 \\
Cusp number & LM2 & $(4) /(5,4)$ & 17.65 \\
\hline
\end{tabular}

* : (Present range of grades)/(total range of grades) 


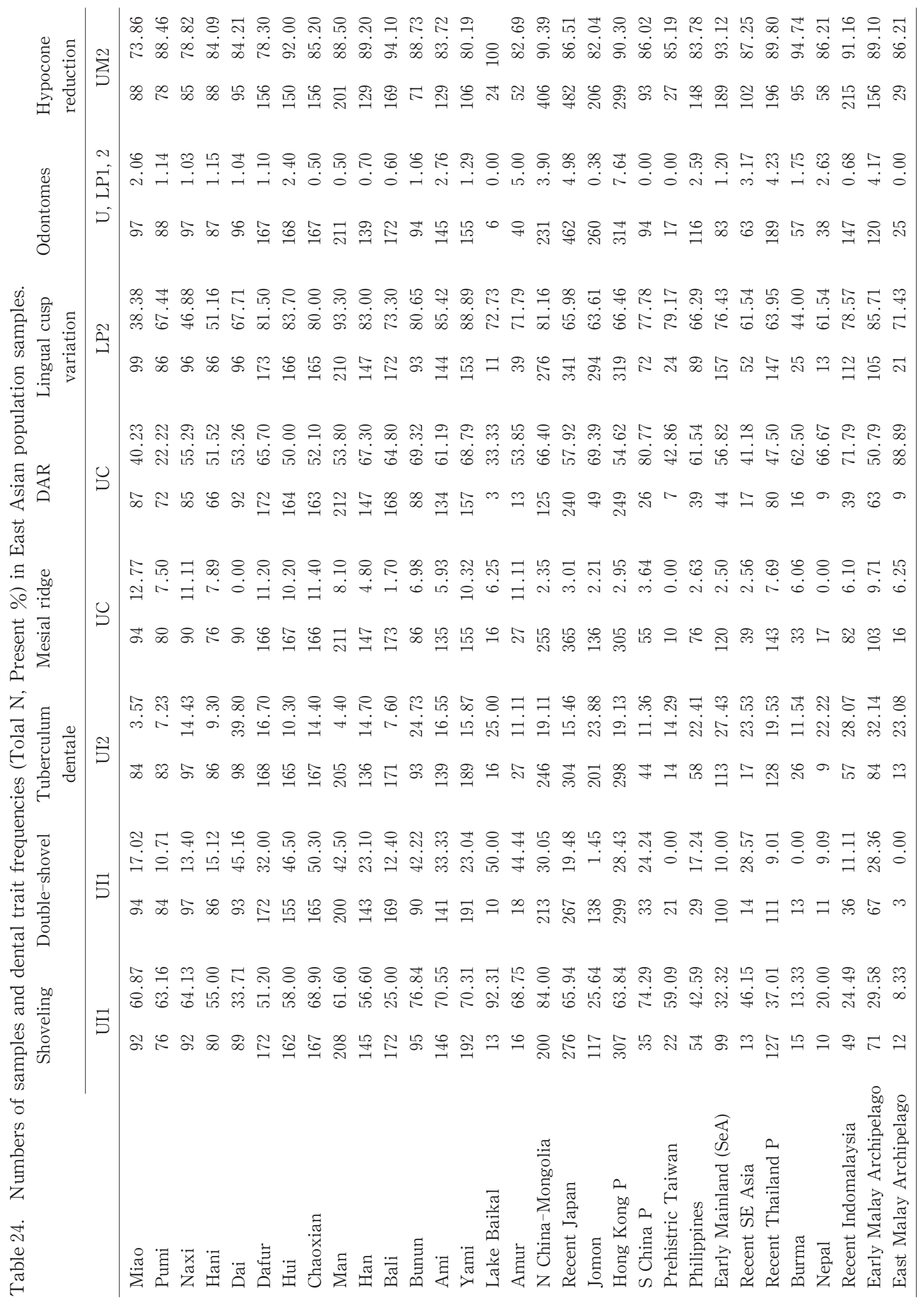




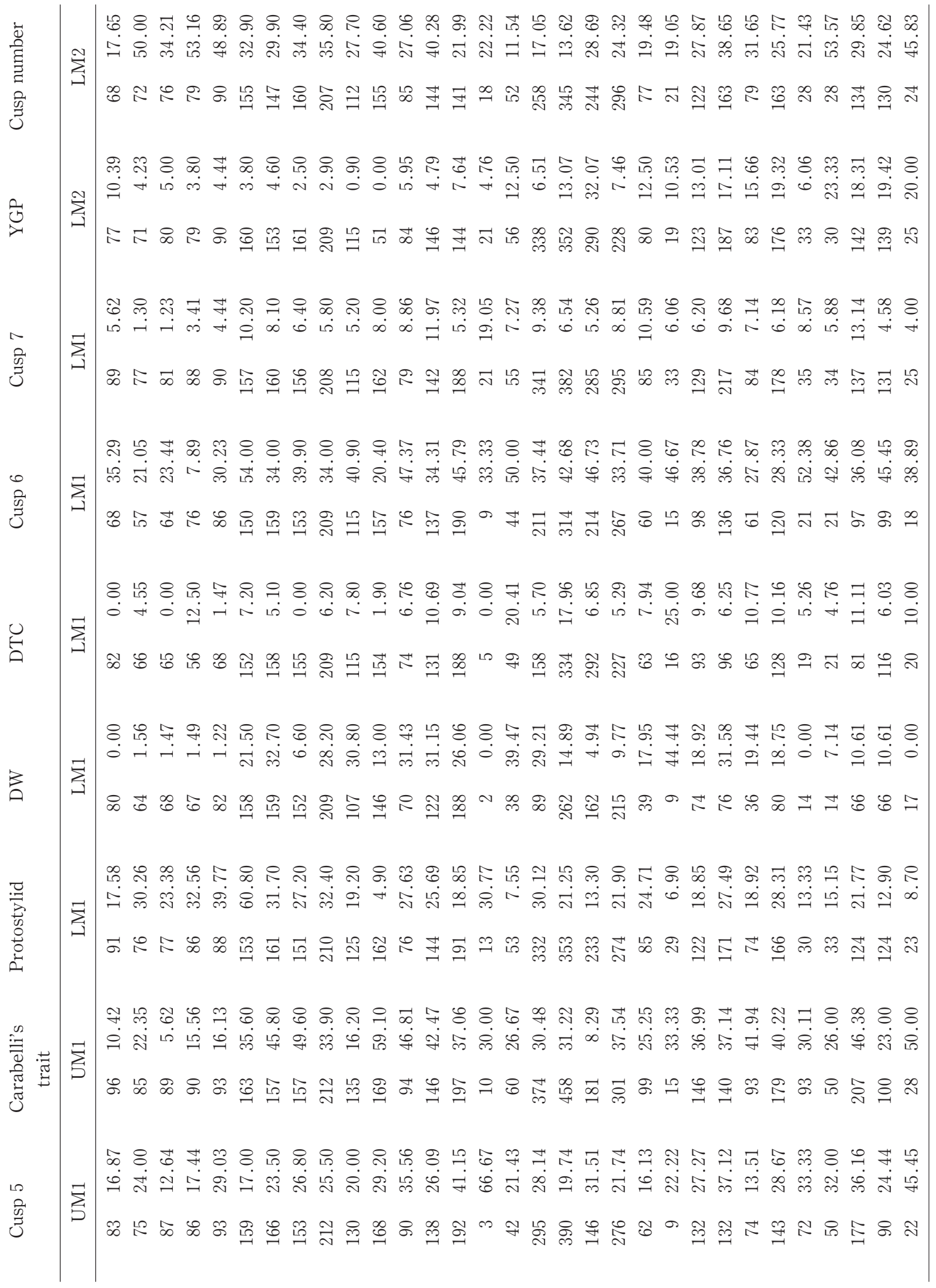




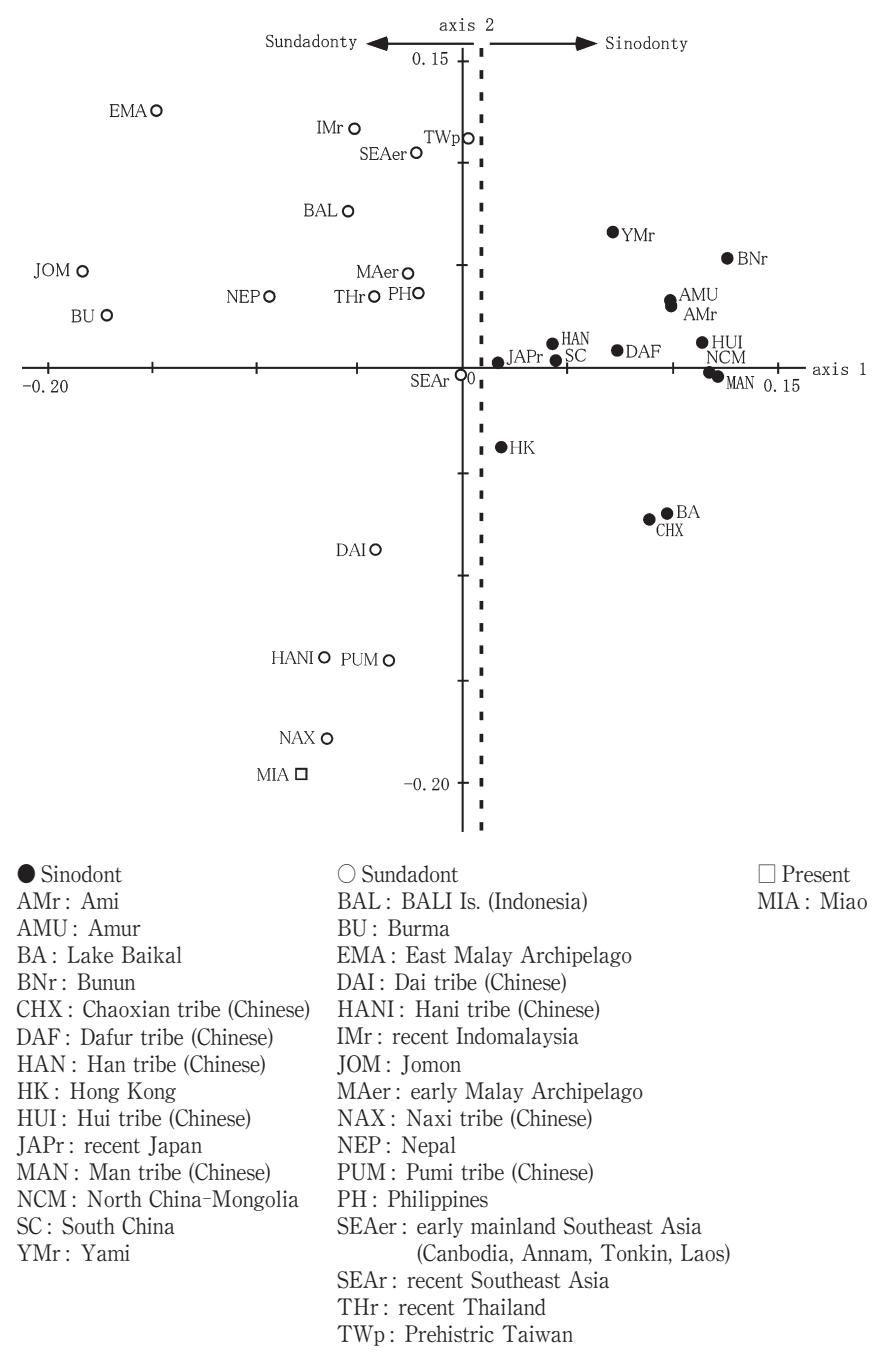

Fig. 1. Two dimensional expression of multidimensional scaling applied to Smith's MMD based on 17 crown traits in 31 Asian populations. Proportion of variation explained by axis 1 and 2 is $36.8 \%$ and $23.1 \%$, respectively.

and Cusp 7 in LM1, and Y groove pattern in LM2, while traits with a relatively low frequency were tuberculum dentale in UI2 and lingual cusp number in LP2, protostylid, DW and DTC in LM1.

The principal coordinate plot for these 17 sets of scores, based on Smith's MMDs and standard deviations, is shown in Fig. 1. Data from Sundadont and Sinodont populations were differently positioned on the right and left half of the first axis. The Miao located in the intermediate position on the first axis between the Sinodont and Sundadont populations, but it deviates slightly in the Sundadont being close to other Chinese minorities, the Naxi.
Table 25. Mesiodistal (MD) and buccolingual (BL) diameters in the Miao.

\begin{tabular}{|c|c|c|c|c|c|c|c|}
\hline \multirow[b]{2}{*}{ D } & \multicolumn{2}{|c|}{ Male } & \multicolumn{4}{|c|}{ Female } & \multirow[b]{2}{*}{$p(\operatorname{sex})$} \\
\hline & $\mathrm{N}$ & Mean & S.D. & $\mathrm{N}$ & Mean & S.D. & \\
\hline Upper I1 & 36 & 8.21 & 0.49 & 58 & 7.95 & 0.61 & $*$ \\
\hline I2 & 36 & 6.61 & 0.82 & 59 & 6.31 & 0.80 & \\
\hline $\mathrm{C}$ & 38 & 7.84 & 0.60 & 60 & 7.64 & 0.50 & \\
\hline $\mathrm{P} 1$ & 38 & 7.20 & 0.41 & 60 & 7.11 & 0.49 & \\
\hline $\mathrm{P} 2$ & 36 & 6.76 & 0.47 & 58 & 6.68 & 0.46 & \\
\hline M1 & 37 & 10.37 & 0.59 & 58 & 10.11 & 0.62 & $*$ \\
\hline M2 & 35 & 9.96 & 0.62 & 51 & 9.47 & 0.60 & $* * *$ \\
\hline M3 & 12 & 8.82 & 0.86 & 12 & 8.19 & 1.15 & \\
\hline Lower I1 & 38 & 5.22 & 0.37 & 62 & 5.16 & 0.44 & \\
\hline $\mathrm{I} 2$ & 38 & 5.90 & 0.49 & 62 & 5.80 & 0.47 & \\
\hline $\mathrm{C}$ & 38 & 7.01 & 0.39 & 62 & 6.55 & 0.42 & $* * *$ \\
\hline $\mathrm{P} 1$ & 38 & 7.12 & 0.43 & 60 & 7.05 & 0.49 & \\
\hline $\mathrm{P} 2$ & 37 & 7.07 & 0.49 & 61 & 6.95 & 0.53 & \\
\hline M1 & 32 & 11.38 & 0.55 & 52 & 10.94 & 0.62 & $* *$ \\
\hline M2 & 36 & 10.77 & 0.66 & 52 & 10.35 & 0.70 & $* *$ \\
\hline M3 & 11 & 10.58 & 0.78 & 12 & 9.87 & 0.77 & $*$ \\
\hline $\mathrm{BL}$ & & & & & & & \\
\hline Upper I1 & 36 & 6.98 & 0.68 & 58 & 6.66 & 0.60 & $*$ \\
\hline I2 & 36 & 5.96 & 0.62 & 59 & 5.77 & 0.77 & \\
\hline $\mathrm{C}$ & 38 & 8.14 & 0.57 & 59 & 7.76 & 0.56 & $* *$ \\
\hline $\mathrm{P} 1$ & 38 & 9.05 & 0.55 & 60 & 8.88 & 0.67 & \\
\hline $\mathrm{P} 2$ & 36 & 9.08 & 0.50 & 58 & 8.88 & 0.68 & \\
\hline M1 & 37 & 11.16 & 0.56 & 59 & 10.87 & 0.64 & $*$ \\
\hline M2 & 36 & 11.56 & 0.65 & 56 & 11.04 & 0.72 & $* * *$ \\
\hline M3 & 16 & 10.85 & 0.67 & 16 & 9.84 & 1.66 & $*$ \\
\hline Lower I1 & 36 & 5.98 & 0.59 & 60 & 5.75 & 0.50 & \\
\hline I2 & 37 & 6.27 & 0.56 & 62 & 6.16 & 0.58 & \\
\hline $\mathrm{C}$ & 36 & 7.89 & 0.60 & 62 & 7.29 & 0.57 & $* * *$ \\
\hline $\mathrm{P} 1$ & 38 & 8.06 & 0.57 & 60 & 7.70 & 0.57 & $* *$ \\
\hline $\mathrm{P} 2$ & 37 & 8.41 & 0.52 & 61 & 8.14 & 0.53 & $*$ \\
\hline M1 & 33 & 10.82 & 0.54 & 54 & 10.41 & 0.62 & $* *$ \\
\hline M2 & 37 & 10.71 & 0.62 & 57 & 10.29 & 0.68 & $* *$ \\
\hline M3 & 13 & 10.45 & 0.79 & 18 & 9.99 & 0.45 & $*$ \\
\hline
\end{tabular}

$* 5 \%, * * 1 \%, * * * 0.1 \%$

Table 25 shows the means and standard deviations of mesiodistal and buccolingual diameters in the Miao, respectively. Both diameters have many significant sex differences, although probabilities were generally higher in buccolingual diameters than in the mesiodistal diameters. 


\section{Discussion}

The population of the Miao, about 8,940,000 now, is larger than most of minority groups in China. After immigration in a long history from Southeast Asian countries, today they live mainly in Guizhou, Yunnan, Hunan, Hubei, Hainan Provinces. They are divided into several branches, such as Black Hmong, White Hmong, Striped Hmong, etc. (1).

The Miao language, which belongs to the MiaoYao group of the Sino-Tibetan phylum, has developed into three dialects. Due to a long time living with the Han and other people, they can also speak the Chinese, Dong and Zhuang languages. They have been writing their own Miao language based on Latin since 1956. The staple food of the Miao ethnic minority is rice. Other dishes are meat and acidic soups. Pickled vegetables, hot seasonings and homemade wine are common at the table (1).

There were two epoch making studies on dental anthropology in Asia: "Mongoloid dental complex (25)" and "proposition of Sundadont and Sinodont (10)." The former explained that Asian people had particular set of teeth called such as shovel-shaped incisor, deflecting wrinkle in lower molars and third molar missing. The latter showed that there were two major morphological variations among Mongoloid populations, Sinodont and Sundadont, describing the combined dental characteristics of the Northeast and Southeast Asian populations, respectively. The Han, the majority of Chinese people, belongs to Sinodont in this context. However, there are 55 minorities in China whose dental anthropological positions have not been known yet.

The dichotomized frequencies of the Miao compared with those of the other East Asian populations revealed that Miao dental characteristics resembled those of Sinodont populations more closely than those of Sundadont populations on UI1 shoveling, while on UI1 double-shoveling and deflecting wrinkle. Miao dental characteristics resembled those of Sundadont populations more closely than those of Sinodont populations. Thus, Miao dentition showed both Sundadont and Sinodont characteristics.

The trait, double-shovelling, characterized by the presence of mesial and distal ridges on the labial surfaces of the upper anterior teeth, is a key trait of the Sinodonty which is said to be developed as an adaptation to a cold climate or hunter-gathering life style $(26,27)$. The frequency of this trait is relatively low in the Miao, placing them in closer affinity to Sundadonty.

Protostylid is also a key trait for Sinodonty (8). This trait appears on the buccal surface of the protoconid of the lower molar. It is frequently, though not invariably, associated with the buccal groove separating protoconid and hypoconid. The lowest frequency of this trait in Miao among 5 minorities indicated their close position to Sundadonty. These results therefore indicate that the Miao occupies an intermediate position between Sundadonty and Sinodonty. High frequencies of Cusp 6 and Cusp7 in LM1 and YGP in LM2 in Miao showed that the Miao retain basic crown characters compared with other minorities.

As in the Fig. 1, the generalized position of the 5 groups of the Chinese minorities occupied lower left corner of the coordinate axis. This implies that these 5 minorities belong to Sundadont, but they are alike in their dental trait frequency, and slightly different from other Sundadont groups.

Thirty East Asian populations compared with the Miao in this study were 15 Sinodont and 16 Sundadont populations. The Northeast and Southeast Asian populations corresponded to Sinodont and Sundadont in Turner's classification were separated out in negative and positive directions on the first principal coordinate of the principal coordinate analysis, as seen in Fig. 1. A multiple regression analysis demonstrated that the first principal coordinate correlated positively with UI1 shoveling, UI1 doubleshoveling, lingual cusp number in LP2 and DW in LM1, on the other hand, the second principal coordinate correlated with DAR in the UC, lingual cusp number in LP2, Cusp 5 and Carabelli's cusp in UM1. The contribution was $36.8 \%$ on the first axis and $23.0 \%$ in the second axis.

A direct comparison of the means of the mesiodistal and buccolingual diameters was done with the use 

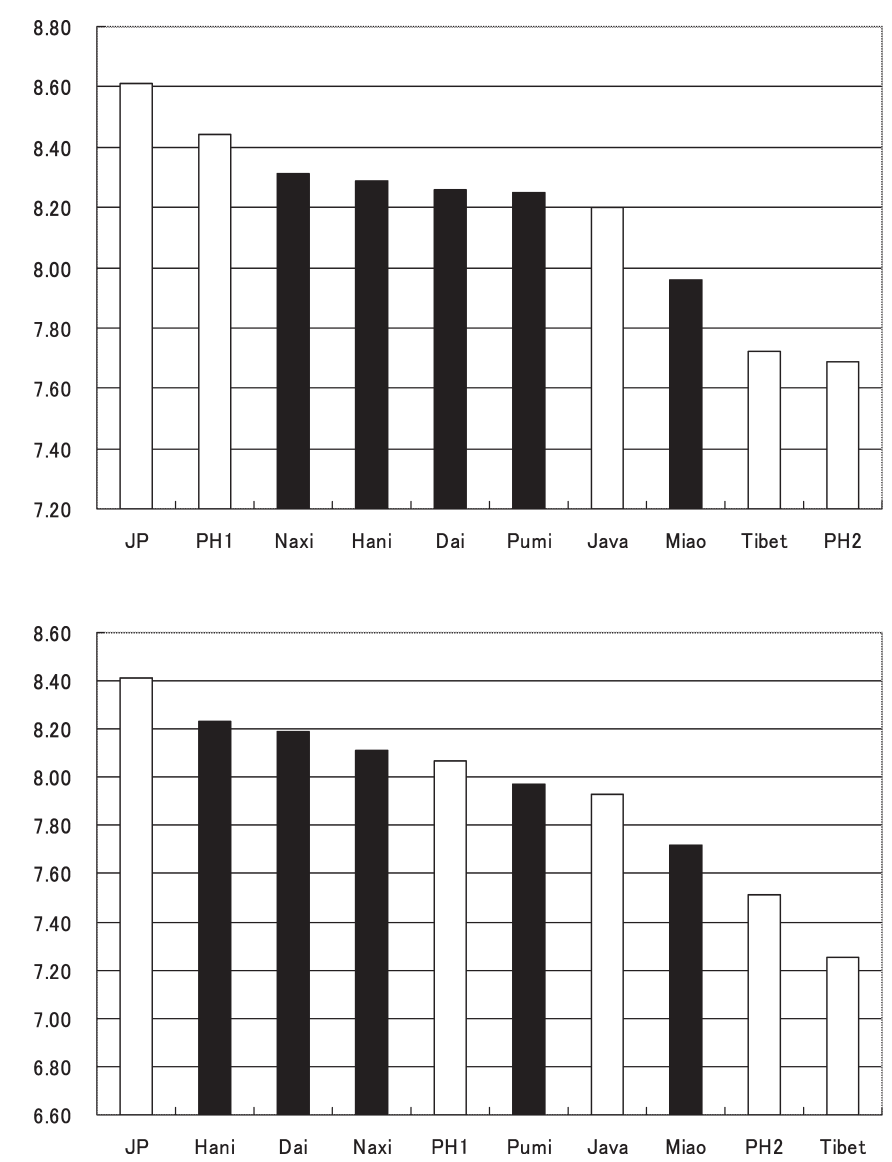

Fig. 2. Mean MD diameter in several Asian populations in males (upper) and females (lower) including Chinese minorities.

of the result of the other minority groups, the Hani and the Dai (28) and the Naxi and the Pumi (29). Both mesiodistal and buccolingual diameters in the Miao were smallest among five groups in almost all teeth in the male and female (data not shown). Fig. 2 shows the inter-population comparison of the tooth size representing the mean of total size of mesiodistal diameters in maxillary teeth from I1 to M2 in Chinese minorities and other Asian populations.

The total tooth size of the Miao showed smallest value among 5 minorities. It has been reported that there is a wide variety of the dimensional characters of the body in Chinese minorities $(3,4)$. The Miao is grouped in the small size group of the body compared with other four groups. For example, averages of the stature (S) and head length (HL) in young adult males in the Miao, Pumi and Dai are as follows:
Miao (S) $153.3 \mathrm{~cm}$ (HL) $18.0 \mathrm{~cm}$, Pumi (S) $166.5 \mathrm{~cm}$ (HL) $19.4 \mathrm{~cm}$, Dai (S) $161.9 \mathrm{~cm}$ (HL) $18.9 \mathrm{~cm}(2,3,4)$ respectively. Direct correlation between tooth size and body size in individuals is not reliable, but they can be compared statistically among peoples with close affinity. The small size of the Miao teeth might reflect their small size of the body.

In Fig. 2, the larger tooth groups than Chinese minorities were Japanese and Philippines 1 which were cited from the studies by ourselves $(28,30)$. Japanese samples were from university students in Chiba, Japan. Philippines 1 was collected from children in highly educated class in Manila (30). The smaller tooth groups were cited from two groups of the Tibet and Philippines. The Tibet sample was cited from Sharma (31) which reported the size of the Tibetan immigrants and described that their teeth were the smallest in the world. The Philippines 2 was cited from our study from Potter (32). Potter's study is also one of the smallest teeth ever reported.

Miao teeth are small among minorities and East Asians, but not so small as in Southeast Asians and Tibetans. It is pointed out that one of the peculiar characters of Sundadonty is the small tooth size compared with Sinodonty. The relatively small size of the teeth in the Miao might suggest that they belong to Sundadont population.

Tooth size varies chronologically and geographically, even in a single populatiton without any change of gene flow (33-38). However, it is also suggested that the current information was inadequate and speculative on the causation of tooth size enlargement in recent populations (39).

The results we obtained for the Miao population showed that it located Sundadont dental variation category, which typifies Southeast Asians. Although anthropological affinity of the Miao tribe is complicated, more detailed dental anthropological studies of minority groups will help the understanding of their history and affinity.

\section{Conclusion}

The frequencies of 22 dental traits and tooth size in Chinese ethnic minority, the Miao tribe were inves- 
tigated. The results were compared with the Dai, Hani, Pumi and Naxi of the Chinese minorities, and those of other Asian populations in terms of Turner's Mongoloid dental variation theory. The traits which showed comparatively high frequency in the Miao were shoveling of the upper central incisor and Cusp 6 while traits with a low frequency were doubleshoveling of the upper central incisor and protostylid in the lower first molar. The tooth size of the Miao was smallest in the 5 Chinese minorities. A principal coordinate analysis based on Smith's Mean Measure of Divergence using the frequencies of the 17 traits, suggested that the Miao tribe occupied the position in the Sundadont dental variation range, which typifies Southeast Asians, but peculiar position among Chinese minorities. Smallest size of the teeth may reflect their ethnic affinity more strongly to Sundadonty.

\section{Acknowledgments}

We are grateful to Professor Eisaku Kanazawa, Department of Anatomy and Physical Anthropology, Nihon University School of Dentistry at Matsudo, for his advice on the conduct of this research and reading the manuscript. Thanks are also to Drs. Kayoko Sasaki and Yuriko Igarashi, Department of Anatomy and Physical Anthropology, Nihon University School of Dentistry at Matsudo, for their assistance in the measurement of teeth and the statistical analysis. This study was supported by a grant-in aid for scientific research from Japan Society for the Promotion of Science, no. 17570197.

\section{References}

1. Hashimoto M, Suzuki H: Han Tribe and Chinese Society, Yamakawa Shuppansha, Tokyo, Japan. 1996. p1-46. (in Japanese)

2. Yu Fachang, Li Ming, Liu Guanhao: Physical Characteristics of Miao Nationality Living in Yunnan Province. Acta Anthrop. Sinica, 13: 321-326, 1994. (in Chinese with English summary)

3. Li Ming, Li Yuemin, Yu Fachang: Physical Characters of Pumi Nationality in Yunnan. Acta Anthrop. Sinica, 14:227-232, 1995. (in Chinese with English summary)

4. Zhang Zhenbiao: An Analysis of the Physical Charac- teristics of Modern Chinese. Acta Anthrop. Sinica, 7 : 314-322, 1988. (in Chinese with English summary)

5. Kawasaki T, Matsuno M: Anthropological Study of Dental Non-metric Traits in the Pumi Minority in China. Int J Oral-Med Sci, 6: 67-76, 2007.

6. Makiguchi H, Matsuno M: Dental Anthropological Study of Non-metric Traits in Dai Nationality of Chinese Minorities. Int J Oral-Med Sci, 3 : 133-142, 2005.

7. Yamazaki T, Matsuno M: Dental Anthropological Study of Non-metric Traits in Naxi Nationality of Chinese Minorities. Int J Oral-Med Sci, 5 : 12-21, 2006.

8. Turner CG II, Nichol CR, Scott GR: Scoring Procedures for Key Morphological Traits of the Permanent Dentition: The Arizona State University Dental Anthropology System, in Advances in Dental Anthropology, Wiley-Liss, New York, 1991, 13-31.

9. Scott, GR, Turner CG II : The Anthropology of Modern Human Teeth, Dental Morphology and its Variation in Recent Human Populations, pp1-31, Cambridge University Press, Cambridge, UK, 1997.

10. Turner CG II : Late Pleistocene and Holocene Population History of East Asia Based on Dental Variation. Am J Phys Anthropol, 73 : 305-321, 1987.

11. Berry AC, Berry RJ : Epigenetic Variation in the Human Cranium. J Anat, 101: 361-379, 1967.

12. Freeman MF, Tukey JW: Transformations Related to the Angular and Square Root. Ann Math Stat, 21 : 607-611, 1950.

13. Green RF, Suchey JM: The Use of Inverse Sine Transformations in the Analysis of Non-metric Cranial Data. Am J Phys Anthrop, 45 : 61-68, 1976.

14. Manabe Y, Ito R, Kitagawa Y, Oyamada J, Rokutanda A, Nagamoto S, Kobayashi S, Kato K: Non-metric Tooth Crown Traits of the Thai, Aka and Yao Tribes of Northern Thailand. Archs oral Biol, 42 : 283-291, 1997.

15. Manabe Y, Rokutanda A, Kitagawa Y: Nonmetric Tooth Crown Traits in the Ami Tribe, Taiwan Aborigines: Comparisons with Other East Asian Populations. Hum Biol, 64 : 717-726, 1992.

16. Manabe Y, Rokutanda A, Kitagawa Y, Oyamada J : Genealogical Position of Native Taiwanese (Bunun Tribe) in East Asian Populations Based on Tooth Crown Morphology. J Anthropol Soc Nippon, 99 : 3347, 1991.

17. Kanazawa E, Shirono Y, Nakayama M, Yamada H, Hanamura H, Kondo S: Distribution of Tubercleshaped Incisors in South Pacific Populations. Anthropological Science, 109: 225-238, 2001.

18. Kobayashi K, Matsuno M: Dental Anthropological Study of Non-metric Traits in the Hani Nationality of Chinese Minorities. Int J Oral-Med Sci, 4 : 61-70, 2005.

19. Chikushi S: Dental Characteristics in the Dafurs 
Tribe of Inner Mongolia, China. J Kyushu Dent Soc, $55:$ 189-205, 2001. (in Japanese)

20. Fukunari F: Dental Characteristics in the Manchu Tribe of Xin-Bin, China. J Kyushu Dent Soc, 53 : 6388, 2003. (in Japanese)

21. Jin $\mathrm{H}$ : Dental Characteristics in the Chaoxian of Liao -Ning Province, China. J Kyushu Dent Soc, 53 : 529537, 2003. (in Japanese)

22. Kikuti N : Dental Characteristics in the Han of LiaoNing, China. J Kyushu Dent Soc, 51 : 193-216, 2003. (in Japanese)

23. Kiyosue T: Dental Characteristics in the Hui of Liao -Ning, China. J Kyushu Dent Soc, 54 : 510-520, 2000. (in Japanese)

24. Yamaguchi Y : Dental Characteristics in Balinese. J Kyushu Dent Soc, 50:663-680, 1996. (in Japanese)

25. Hanihara K : Mongoloid Dental Complex in the Deciduous Dentition. J Anthrop Soc Nippon, 74:61-72, 1966.

26. Mizoguchi Y: Shoveling: A Statistical Analysis of Its Morphology, University of Tokyo Press, Tokyo, 1985.

27. Dahlberg AA, Mikkelson O: The Shovel-shaped Character in the Teeth of the Pima Indians. Am J Phys Anthrop, 5: 234-5, 1947.

28. Matsuno M, Kanazawa E, Nakayama M, Ohsako M, Shizushima A, Kawasaki T, Yamashita M, Sasaki K, Ji X, Guo D: Tooth Size of Chinese Minorities, Hani and Dai Tribes in Yunnan Province. Int J Oral-Med Sci, 4: 21-27, 2005.

29. Kanazawa E, Matsuno M, Nakayama M, Shizushima A, Kawasaki T, Ichikawa H, Yamazaki T, Sasaki K, Ji Xueping, Guo Dalie: Tooth Size of Chinese Ethnic Minorities, Naxi and Pumi in Yunnan Province, Current Trends in Dental Morphology Research, Univer- sity of Lodz Press, Poland, pp89-96, 2005.

30. Majima A: Odontometric Study of Philippine Negritos and Modern Filipinos. Nihon Univ J Oral Sci, 25: 165-173, 1999.

31. Sharma JC: Dental Morphology and Odontometry of Tibetan Immigrants. Am J Phys Anthrop, 61: 495505.

32. Potter RH, Alcazaren AB, Herbosa FM, Tomaneng J : Dimensional Characteristics of the Filipino Dentition. Am J Phys Anthrop, 55 : 33-42, 1981.

33. Corruccini RS, Lee GTR: Occlusal Variation in Chinese Immigrants to the United Kingdom and Their Offspring. Arch Oral Biol, 29: 779-782, 1984.

34. Garn SM, Lewis AB, Walenga A: Evidence for a Secular Trend in Tooth Size over Two Generations. J Dent Res, 47 : 503-503, 1968.

35. Kieser JA, Groeneveld HT, Cameron N : Evidence for a Secular Trend in the Negro Dentition. Ann Hum Biol, 14 : 517-532, 1984.

36. Takahashi M, Nakayama M, Matsuno M, Igarashi Y, Sasaki K, Satake T, Kanazawa E: Generation Difference in Tooth Size and Tooth Eruption Timing between Two Elementary Schools. Jap J Pediatric Dent, 43: 85-93, 2005

37. Kanazawa E: Tooth Size Change in Recent Generations of Fiji. Proceedings for VIII Pacific Science Congress, The University of the South Pacific, Suva, Fiji, p175, 1997.

38. Kanazawa E, Matsuno M, Nakabayashi T, Igarashi Y, Nagai A: Tooth Size of Living Peoples in Western and Eastern Micronesian Populations. Anthropol Sci, 106 : 199-208, 1998.

39. Kieser JA : Human Adult Odontometrics, Cambridge University Press ; Cambridge, 1990. p50-62. 